\title{
Anxiolytic Effect of Cedrol on Behavior and Brain Neurotransmitter Levels of Female Mice
}

\author{
Kai Zhang and Lei Yao* \\ School of Agriculture and Biology, Shanghai Jiao Tong University; 800 Dongchuan Rd. Minhang District, Shanghai \\ 200240, China.
}

Received May 9, 2019; accepted June 19, 2019; advance publication released online June 29, 2019

Cedrol has been reported to be effective in reducing anxiety of male mice. The limited application of females in animal models of anxiety makes it difficult to systematically investigate new drug substitutes with potential anxiolytic activity. In the present study, we investigated the behavioral response of female ICR mice to cedrol after intraperitoneal (i.p.) administration using the elevated plus maze (EPM) and the light-dark box (LDB) test, followed by determination of neurochemical changes in brain. The data suggested that cedrol at dose of $1200-1600 \mathrm{mg} \cdot \mathrm{kg}^{-1}$ exhibited anxiolytic activity on the female mice, as reflected by greater percentage of entries into the open arms and time spent in the open arms in the EPM, and greater transitions between chambers and percentage of time spent in the light chamber in the LDB. Cedrol increased the level of 5-hydroxytryptamine (5-HT), decreased the level of dopamine (DA), reduced the ratio of 5-hydroxyindoleacetic acid (5-HIAA)/5-HT and increased the ratio of 3,4-dihydroxyphenyl acetic acid (DOPAC)/DA, compared with the control group, indicative of an anxiolytic-like effect on female mice via the 5-HTnergic or DAnergic pathways.

Key words anxiolytic effect; cedrol; 5-hydroxytryptamine; elevated plus maze; light-dark box

\section{INTRODUCTION}

Essential oils (EOs) are traditionally used in aromatherapy, an important complementary therapy, to treat mental disorders such as epilepsy, insomnia or anxiety. ${ }^{1-3)}$ Compared with some psychotropic medicines extensively in use, EOs have attracted more attention owing to their fewer adverse effects. ${ }^{4,5)}$ Lots of references have indicated that the anxiolytic effect of EOs could be attributed to their main active components, such as citronellol and 2-phenethyl alcohol in rose oil,,67) linalool in lavender oil, ${ }^{8,9)}$ and limonene in orange oil, ${ }^{5,10)}$ nevertheless, specific mechanisms of EOs seem to be complicated due to the characteristic components in EOs, which may exhibit synergistic or antagonistic effects.

EOs or their main active components not only modify the contents of neurotransmitters, but also modulate their uptake or release. Hypericum perforatum L. (St. John's wort) oil was reported to increase 5-hydroxytryptamine (5-HT) concentration of basal nuclei. ${ }^{11)}$ Lemon oil was proved to reduce the dopamine (DA) level, which is associated with the serotonergic (5-HTnergic) neurons activity. ${ }^{12)}$ Linalool, the major component of lavender oil, was demonstrated to have an inhibitory effect on the glutamatergic transmission in the rat cerebral cortex. $^{13)}$

Cedrol, primarily derived from eastern redcedar (Juniperus virginiana L.) essential oil (ERO), has a light woody aroma. Several references have highlighted its impact on the behavioral and autonomic activities of mammals, by suppressing sympathetic outflow and increasing parasympathetic outflow. ${ }^{14-16)}$ In human experiments, cedrol inhalation increased the parasympathetic activity and decreased the sympathetic activity. ${ }^{14)}$ In animal experiments, exposure to cedrol appeared to induce a sedative effect regardless of the animal species. ${ }^{17,18)}$

Therefore, we surmised that cedrol might have relaxant and anxiolytic properties. This hypothesis was supported by our previous study, in which we demonstrated, in animal models of anxiety, that intraperitoneal (i.p.) administration of ERO and cedrol exhibited an anxiolytic effect on male ICR mice, via the 5-HTnergic and dopaminergic (DAnergic) pathways. ${ }^{19}$ ) However, the anxiolytic effect of cedrol on female mice is still unknown.

In preclinical experiments or commonly-used behavioral tests, especially in the field of brain and behavior, female animals have often been omitted deliberately due to their own estrous cycle. ${ }^{20-22)}$ This limited application of females in behavioral experiments, the study on the anxiolytic activity of EOs, for instance, thus results in the presence of sexually dimorphic patterns of prevalence and/or severity, ${ }^{22)}$ as well as the lack of systematic studies on the underlying mechanism of anxiety behaviors. ${ }^{20,23,24)}$

The main objective of the present study was to evaluate the anxiolytic effect of cedrol on female ICR mice via the elevated plus maze (EPM) and light-dark box (LDB) paradigm. Moreover, we evaluated neurochemical changes, which are associated with the anxiolytic effect, by measuring the contents of 5-HT, DA and their metabolites in brains.

\section{MATERIALS AND METHODS}

Experimental Animals Female ICR mice, aged 5-6 weeks, obtained from Laboratory Animal Center of Shanghai Jiao Tong University were used. Prior to experiments, mice were maintained for one week ( 5 mice per cage), under controlled temperature $\left(25 \pm 1{ }^{\circ} \mathrm{C}\right)$, light $(12 \mathrm{~h} / 12 \mathrm{~h}$ light/dark cycle) and humidity (with $50 \pm 5 \%$ ) conditions, with food and water ad libitum. Females were randomly selected to submit to behavioral tests. All the behavioral tests were carried out between 11:00 a.m. and 4:00 p.m. to minimize the influence of 
dynamic change in hormone.

All the experimental procedures were manipulated in accordance with the Association for Assessment and Accreditation of Laboratory Animal Care International and approved by the Institutional Animal Care and Use Committee of Shanghai Jiao Tong University.

Drugs and Treatments Cedrol was obtained from Jiangxi Global Natural Spices Co., Ltd. (Jiangxi, China). Diazepam (DZP) was purchased from Shanghai Xudong Haipu Pharmaceutical Co., Ltd. (China). DZP or cedrol were dissolved in olive oil (OO), which did not alter the anxiolytic-like parameters (data not published). Thirty minutes prior to the test sessions, olive oil (control), DZP $\left(2 \mathrm{mg} \cdot \mathrm{kg}^{-1}\right.$, positive control) and cedrol $\left(200,400,800,1200\right.$ and $\left.1600 \mathrm{mg} \cdot \mathrm{kg}^{-1}\right)$ were i.p. administrated at a dosage of $0.1 \mathrm{~mL} / 10 \mathrm{~g}$ body weight, with which we could avoid animal's preferences and sensitivity to odorous components, according to the previous reports. ${ }^{25-27)}$ The drug doses were selected based on pilot data in our laboratory. All efforts were made to minimize the number of animals and their suffering.

EPM The EPM, utilized extensively to examine the anti-anxiety effect of both traditional and non-traditional anxiolytic agents, ${ }^{28)}$ is based on rodent's conflict between the innate fear of open areas and the drive to explore the novel places. ${ }^{29)}$ The maze was designed as described with several structural modifications. ${ }^{30)}$ The apparatus consisted of two open arms $(30 \times 6 \mathrm{~cm}$, length $\times$ width $)$ and two closed arms $(30 \times 6 \times 15 \mathrm{~cm}$, length $\times$ width $\times$ height $)$ connected by an open central platform $(6 \times 6 \mathrm{~cm}$, length $\times$ width $)$. The maze was elevated $55 \mathrm{~cm}$ above the floor and placed inside a soundattenuated room. $30 \mathrm{~min}$ after the administration, mouse was individually placed on the platform. Behavior of each animal was recorded for $5 \mathrm{~min}$ via a video camera above the EPM.

The anxiety parameters were determined as described in the previous study. ${ }^{5)}$ The number of entries and the time spent in open or closed arms were evaluated. The percentage of entries into the open arms $(\mathrm{OAE} \%)$ and the percentage of time spent in the open arms (OAT\%) were calculated as anxiety parameters. Subsequently, the distance travelled in the model was recorded as a measure of locomotor activity. An entry was defined when the animal stepped into an arm with its four paws at a given time. ${ }^{31)}$

LDB The LDB, used to test unconditioned anxiety and exploratory behavior, is based on the innate aversion of mice to bright light in novel areas. ${ }^{32}$ ) The box was designed as described with several structural modifications. ${ }^{33)}$ The apparatus consisted of a plywood box divided by a connecting door $(5 \times 5 \mathrm{~cm}$, length $\times$ height $)$ into a light chamber
$(27 \times 18 \times 18 \mathrm{~cm}$, length $\times$ width $\times$ height $)$ and a dark chamber $(18 \times 18 \times 18 \mathrm{~cm}$, length $\times$ width $\times$ height $)$. The light chamber was entirely painted white and illuminated with 4001x. After the EPM test, the animal was immediately placed in the center of the light chamber. Behavior was monitored for $5 \mathrm{~min}$ via the micro-camera in the top of chamber cover.

The anxiety parameters were defined according to the previous study. ${ }^{5}$ The time spent in each chamber and the number of transitions between chambers was registered, respectively. The percentage of time spent in the light chamber (LCT\%) was calculated. The distance travelled in the model was also recorded.

Evaluation of Monoamines and Their Metabolites in Brain After the LDB test, mice were immediately euthanized to extract the whole brain. Tissues were homogenized in a solution containing $0.2 \mathrm{M}$ perchloric acid, $0.2 \mathrm{mM}$ sodium pyrosulfite and $0.01 \%$ ethylenediamine tetraacetic acid disodium salt $(\text { EDTA-Na })_{2}$ ) together with $0.3 \mu \mathrm{M} \mathrm{3,4-dihydroxy-}$ benzylamine hydrobromide (DHBA) as an internal standard, and then centrifuged at $10000 \times \boldsymbol{g}$ for $20 \mathrm{~min}$ at $4^{\circ} \mathrm{C}$. The supernatants were collected and stored at $-80^{\circ} \mathrm{C}$.

The procedure of determination was carried out as described in the literatures with several modifications. ${ }^{19,34-36)}$ DA, 5-HT, norepinephrine (NE), 3,4-dihydroxyphenyl acetic acid (DOPAC), 5-hydroxyindoleacetic acid (5-HIAA) and homovanillic acid (HVA) were determined by HPLC with an electrochemical detector (LC-4C, BAS, U.S.A.). Separation was performed on a TMRP18 column $(4.6 \times 250 \mathrm{~mm}, 5.0 \mu \mathrm{m}$, GL Science, Japan). The mobile phase (methanol-water, 16:84, $\mathrm{v} / \mathrm{v})$, mixed with sodium 1-octanesulfonate, sodium acetate and citric acid, was delivered at rate of $1 \mathrm{~mL} \cdot \mathrm{min}^{-1}$. The concentrations of neurotransmitters were calculated by the calibration curve of external standards.

Statistical Analysis Animals' behaviors in the EPM and LDB tests were recorded and analyzed using the SuperMaze video tracking system (XR-Xmaze, Xinruan information technology Co., Ltd., China). Overall differences in behavioral procedures and contents of neurotransmitters were examined by one-way ANOVA followed by Tukey's post hoc test to evaluate the anxiolytic effect of cedrol. $p<0.05$ was established as the significant level.

\section{RESULTS}

Effect of Cedrol on Female Mice Behavior in the EPM Test The ANOVA for OAE\% (Fig. 1A) revealed significant differences among the treatment groups $(F(6,49)=10.567$, $p<0.001)$. Female mice treated with DZP $(p<0.001)$, and
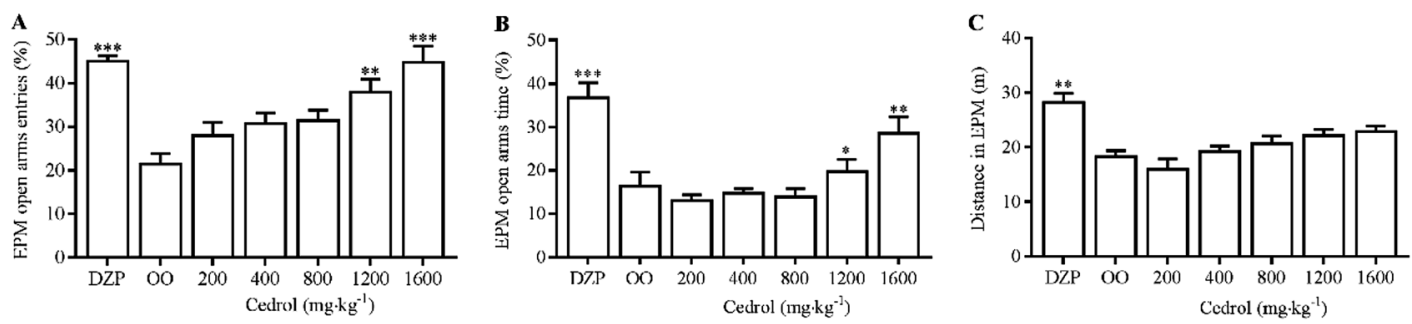

Fig. 1. The Anxiolytic Effect of Cedrol on Female Mice in the EPM Test

Effect of cedrol $\left(200,400,800,1200\right.$ and $1600 \mathrm{mg} \cdot \mathrm{kg}^{-1}$, i.p.) on the percentage of entries into the open arms (A), the percentage of time spent in the open arms (B), distance travelled (C). DZP: diazepam, $2 \mathrm{mg} \cdot \mathrm{kg}^{-1}$ (i.p.); OO: olive oil (i.p.). Results are expressed as mean \pm standard error of the mean (S.E.M.) $(n=8$ per group). $* p<0.05$, $* * p<0.01, * * * p<0.001$ vs. the olive oil group. 

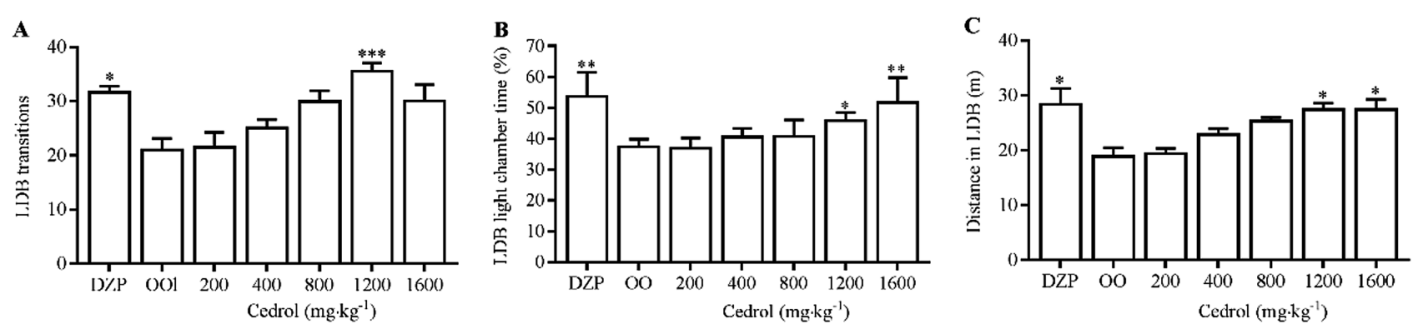

Fig. 2. The Anxiolytic Effect of Cedrol on the Female Mice in the LDB Test

Effect of cedrol $\left(200,400,800,1200\right.$ and $1600 \mathrm{mg} \cdot \mathrm{kg}^{-1}$, i.p.) on the transitions between chambers (A), the percentage of time spent in the light chamber (B), distance travelled (C). DZP: diazepam, $2 \mathrm{mg} \cdot \mathrm{kg}^{-1}$ (i.p.); OO: olive oil (i.p.). Results are expressed as mean \pm S.E.M. $\left(n=8\right.$ per group). ${ }^{*} p<0.05, * * p<0.01, * * * p<0.001 v s$. the olive oil group.
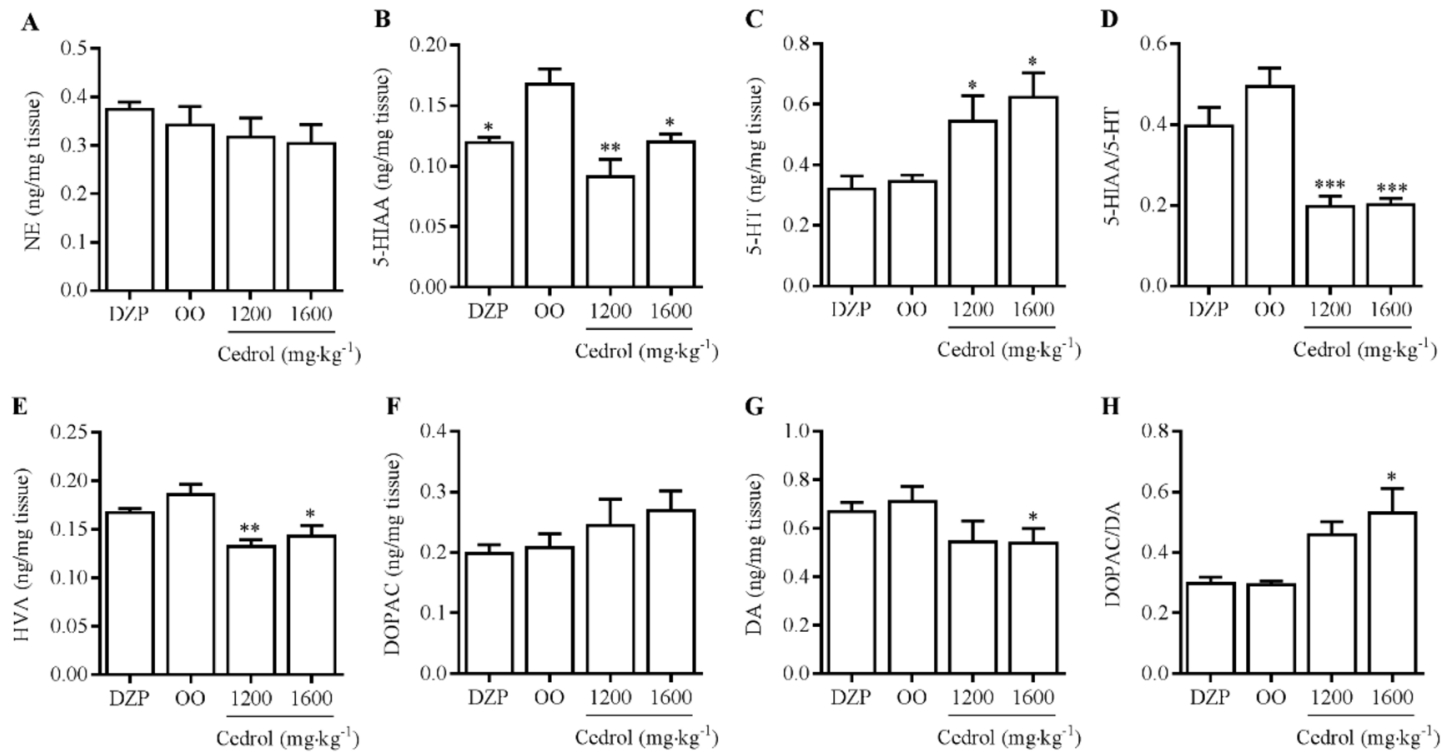

Fig. 3. Changes of Monoamines and Their Metabolites in the Brains of Female Mice

Concentrations of NE (A), 5-HIAA (B), 5-HT (C), the ratio of 5-HIAA/5-HT (D), HVA (E), DOPAC (F), DA (G) and the ratio of DOPAC/DA (H). DZP: diazepam, $2 \mathrm{mg} \cdot \mathrm{kg}^{-1}$ (i.p.); OO: olive oil (i.p.). Results are expressed as mean \pm S.E.M. ( $n=8$ per group). $* p<0.05, * * p<0.01, * * * p<0.001 v s$. the olive oil group.

cedrol at dose of $1200 \mathrm{mg} \cdot \mathrm{kg}^{-1}(p<0.01)$ and $1600 \mathrm{mg} \cdot \mathrm{kg}^{-1}$ $(p<0.001)$ entered more into the open arms when compared with the OO group. Same analysis for the parameter OAT $\%$ showed differences among groups $(F(6,49)=10.992$, $p<0.001)$, namely DZP $(p<0.001), 1200 \mathrm{mg} \cdot \mathrm{kg}^{-1} \quad(p<0.05)$ and $1600 \mathrm{mg} \cdot \mathrm{kg}^{-1}(p<0.01)$ groups spent more time in the open arms than OO group (Fig. 1B). DZP significantly increased the total exploration distance in the EPM $(p<0.01)$, whereas no significant differences were observed among cedrol treatments (Fig. 1C). It was assumed that cedrol (1200 and $1600 \mathrm{mg} \cdot \mathrm{kg}^{-1}$ ) exhibited an obvious anxiolytic effect in the EPM test, with exclusion of the influence on locomotor activity.

Effect of Cedrol on Female Mice Behavior in the LDB Test The ANOVA for the transitions between chambers (Fig. 2A) presented significant differences among the treatment groups $(F(6,49)=6.452, p<0.001)$. Female mice treated with DZP $(p<0.05)$ and cedrol at dose of $1200 \mathrm{mg} \cdot \mathrm{kg}^{-1}$ $(p<0.001)$ performed more transitions than OO group. The same analysis for the parameter LCT\% (Fig. 2B) also showed differences among groups $(F(6,49)=3.665, p<0.01)$, namely DZP $(p<0.01), 1200 \mathrm{mg} \cdot \mathrm{kg}^{-1} \quad(p<0.05)$ and $1600 \mathrm{mg} \cdot \mathrm{kg}^{-1}$ $(p<0.01)$ groups spent more time in the light chamber than the $\mathrm{OO}$ group. Figure $2 \mathrm{C}$ revealed that DZP markedly increased the total exploration distance in the LDB $(p<0.05)$, in addition, cedrol at dose of 1200 and $1600 \mathrm{mg} \cdot \mathrm{kg}^{-1}$ produced a similar profile with DZP ( $p<0.05, p<0.05$, respectively). These findings showed that cedrol $\left(1200\right.$ and $\left.1600 \mathrm{mg} \cdot \mathrm{kg}^{-1}\right)$ exhibited a significant anxiolytic effect in the LDB test, with an increase on locomotor activity.

Changes of Monoamines and Their Metabolites in Brain Results from the evaluation of monoamine neurotransmitters in the brains of female mice were shown in Fig. 3. Cedrol at dose of 1200 and $1600 \mathrm{mg} \cdot \mathrm{kg}^{-1}$ (Figs. 3B-E) significantly reduced the level of 5-HIAA $(F(3,28)=7.727, p<0.01)$, the ratio of 5 -HIAA/5-HT $(F(3,28)=6.829, p<0.001)$, the level of HVA $(F(3,28)=7.879, p<0.01)$ and elevated the level of 5 -HT $(F(3,28)=5.703, p<0.01)$, when compared with the control group. Meanwhile, cedrol at dose of $1600 \mathrm{mg} \cdot \mathrm{kg}^{-1}$ significantly decreased the level of DA $(F(3$, $28)=1.835, p<0.05)$, and increased the ratio of DOPAC/DA $(F(3,28)=6.186, p<0.01)$, when compared with the control group (Figs. $3 \mathrm{G}, \mathrm{H}$ ). No significant changes were seen in the levels of $\mathrm{NE}(F(3,28)=0.827, p>0.05)$ and DOPAC $(F(3$, $28)=1.216, p>0.05)($ Figs. 3A, F).

\section{DISCUSSION}

The present work has clearly shown the anxiolytic effect of cedrol on female mice through the EPM and LDB tests. 
Though no significant anxiolytic effects were observed at $200-800 \mathrm{mg} \cdot \mathrm{kg}^{-1}$ on the ethological measures, cedrol at dose of $1200-1600 \mathrm{mg} \cdot \mathrm{kg}^{-1}$ significantly increased the parameters of anxiolytic-like activity evaluated in both EPM and LDB tests. According to the hypothesis that the biological properties of EOs could be attributed to their main active constituents, ${ }^{34)}$ the results above further strengthened the fact that Juniperus virginiana L. essential oil or cedrol possesses anxiolytic effect.

Many animal anxiety models are based on behaviors that depend on body activity and locomotor activity in apparatus, which partially illustrates that it is difficult to dissociate a pure measure of emotionality from non-emotional confounding factors (e.g., motor activity-distance travelled). ${ }^{37)} \mathrm{A}$ number of studies have employed distance travelled in models to assess locomotor activity. ${ }^{5,35,38)}$

We employed the distance travelled in EPM and LDB as a covariate for accurate and reliable statistical analysis of anxiolytic parameters. Cedrol failed to increase the distance travelled in the EPM, whereas 1200 and $1600 \mathrm{mg} \cdot \mathrm{kg}^{-1}$ of cedrol significantly increased the distance parameter in LDB test $(p<0.05)$, displaying a slightly greater locomotor activity. The discrepancy might be caused by the difference in the application of animal models of anxiety.

The correlation between neurotransmitters and anxiety has been well documented in many references, in which monoamines and their metabolites in the central nervous system are associated with the modulation of anxiety disorder. ${ }^{34,39,40)}$ Decreased DA level ${ }^{41)}$ and increased $\gamma$-aminobutyric acid (GABA) level ${ }^{42,43)}$ or 5-HT level ${ }^{34)}$ indicate an anxiolytic-like effect. Strikingly, changes in monoamines and their metabolites in the present study tended to follow the same trend in the previous research.

As expected, cedrol functioned through the 5-HTnergic system, since it enhanced the level of 5-HT, accompanied with the decreased 5-HIAA level. Likewise, the lower ratio of 5-HIAA/5-HT suggested that cedrol could accelerate the synthesis of 5-HT in female mice. However, we cannot discard the possibility that cedrol also acted via DAnergic system. The decreased DA level and increased DOPAC/DA ratio were observed at $1600 \mathrm{mg} \cdot \mathrm{kg}^{-1}$ group. It has been reported that 5-HT and DA fibers normally compete for target sites in striatum, and DA might suppress the 5-HT axon growth. ${ }^{41,44,45)} \mathrm{We}$ can infer that cedrol might affect the DAergic neuron by activating 5-HTergic neuron. A previous study proposed a similar mechanism, in which lemon oil vapor possibly affected the response to DAnergic activity by modulating the 5-HTnergic system. ${ }^{12)}$

Female mice intrinsically were less responsive to cedrol, when compared with male ICR mice in our previous study, in which cedrol administration (i.p.) produced significant anxiolytic effect in both EPM and LDB tests (400-1600 and $800-1600 \mathrm{mg} \cdot \mathrm{kg}^{-1}$, respectively), as well as increased the distance travelled in apparatuses at $200-1600 \mathrm{mg} \cdot \mathrm{kg}^{-1} \cdot{ }^{19}$ )

Though the basic neurobiology of anxiety may be similar between males and females, sex differences in sensitivity to certain anxiolytic drugs or substitutes have been acknowledged in many preclinical experiments. ${ }^{46,47)}$ For example, DZP $\left(1 \mathrm{mg} \cdot \mathrm{kg}^{-1}\right)$ was more effective in males than females, ${ }^{48}$ suggesting that the therapeutic effects of benzodiazepines are closely related with sex and hormone cycle stage. ${ }^{49}$ Zhang et $a l .{ }^{35}$ ) demonstrated that ylang-ylang (Cananga odorata (LAm.) Hoок. f. \& THOMson) essential oil showed significant anxiolytic effect on the male ICR mice. Sex difference was also observed in the EPM test in gerbils after rose essential oil exposure.7)

The gonadal hormone contributed to the gender-specific anxiety behaviors. For example, testosterone exhibited anxiolytic effect through androgen receptor, ${ }^{50)}$ and estrogen decreased the anxiety level in females. ${ }^{51)}$ Previous researches also proved that estradiol eliminated difference in OAT\% between proestrous and diestrous rats. ${ }^{52)}$ In addition, estradiol administration elicited anxiolytic and antidepressant-like effects on ovariectomized rats, ${ }^{51)}$ or enhanced the oxytocininduced anxiolytic effect in mice. ${ }^{53)}$

The effect of estrogen action on anxiety might associated with the estrous cycle stage. Females seemed to be more anxious during the metestrous and diestrous phases, compared with proestrous and estrous phases. ${ }^{52,54)}$ Similarly, the activational effect of estrogen augments the hypothalamic-pituitary-adrenal (HPA) axis response to increase the level of estrogen. ${ }^{55)}$ Aoki et al. ${ }^{56)}$ hypothesized that ovary-derived factors (but not $17 \beta$-estradiol) controlled the HPA axis response in female ICR mice.

Some investigations also indicated that estrogen, but not testicular hormones, significantly modulated DA level of females over the estrous cycle, instead of castrated males. ${ }^{41,57-59)}$ Shams et $a .^{60)}$ and Becker ${ }^{61)}$ proposed that $17 \beta$-estradiol increased DA transmission in the dorsal striatum of ovariectomized rats. In addition, when $5-\mathrm{HT}_{1 \mathrm{~A}}$ receptor antagonists were co-administered with estradiol, the behavioral effects of estradiol treatment were attenuated. ${ }^{62)}$ These results provide some possible mechanism basis for our further hypothesis.

In view of this, we proposed the possible mechanism of anxiolytic effect of cedrol on female mice: cedrol was absorbed into blood, then carried to the brain area, acted on the HPA axis, with which cedrol facilitated the release of estrogen, that induced an increased 5-HT level or decreased DA level in brain. Synergism or antagonism between hormone and cedrol administration on mice should be considered in the next experiment.

\section{CONCLUSION}

All these things considered, cedrol possesses a significant anxiolytic effect on female mice in the EPM and LDB tests, without significant suppression on locomotor activity. The anxiolytic effect might be caused by accelerating the synthesis of 5-HT and suppressing the synthesis of DA.

Acknowledgments This work was supported by a Grant from the funding for fostering key projects and innovation research team from the Shanghai Jiao Tong University [Grant number 12X190030006]. We are grateful to the animal caretakers of the Laboratory Animal Center of Shanghai Jiao Tong University, Xiaohong Ma and Nan Zhang for their assistance during animal experiments.

Conflict of Interest The authors declare no conflict of interest. 


\section{REFERENCES}

1) Bakkali F, Averbeck S, Averbeck D, Idaomar M. Biological effects of essential oils-A review. Food Chem. Toxicol., 46, 446-475 (2008).

2) Adorjan B, Buchbauer G. Biological properties of essential oils: an updated review. Flavour Fragrance J., 25, 407-426 (2010).

3) Patel S, Gogna P. Tapping botanicals for essential oils: Progress and hurdles in cancer mitigation. Ind. Crops Prod., 76, 1148-1163 (2015).

4) Orriols L, Salmi L, Philip P, Moore N, Delorme B, Castot A, Lagarde E. The impact of medicinal drugs on traffic safety: a systematic review of epidemiological studies. Pharmacoepidemiol. Drug Saf., 18, 647-658 (2009).

5) Faturi CB, Leite JR, Alves PB, Canton AC, Teixeira-Silva F. Anxiolytic-like effect of sweet orange aroma in Wistar rats. Prog. Neuropsychopharmacol. Biol. Psychiatry, 34, 605-609 (2010).

6) Umezu T, Ito H, Nagano K, Yamakoshi M, Oouchi H, Sakaniwa M, Morita M. Anticonflict effects of rose oil and identification of its active constituents. Life Sci., 72, 91-102 (2002).

7) Bradley BF, Starkey NJ, Brown SL, Lea RW. The effects of prolonged rose odor inhalation in two animal models of anxiety. Physiol. Behav., 92, 931-938 (2007).

8) Shaw D, Annett JM, Doherty B, Leslie JC. Anxiolytic effects of lavender oil inhalation on open-field behaviour in rats. Phytomedicine, 14, 613-620 (2007).

9) Perry R, Terry R, Watson LK, Ernst E. Is lavender an anxiolytic drug? A systematic review of randomised clinical trials. Phytomedicine, 19, 825-835 (2012).

10) Lima NGPB, De Sousa DP, Pimenta FCF, Alves MF, De Souza FS, Macedo RO, Cardoso RB, de Morais LCSL, Melo Diniz MDFF, de Almeida RN. Anxiolytic-like activity and GC-MS analysis of $(R)$ $(+)$-limonene fragrance, a natural compound found in foods and plants. Pharmacol. Biochem. Behav., 103, 450-454 (2013).

11) Gobbi M, Dalla Valle F, Ciapparelli C, Diomede L, Morazzoni P, Verotta L, Caccia S, Cervo L, Mennini T. Hypericum perforatum L. extract does not inhibit 5-HT transporter in rat brain cortex. Naunyn Schmiedebergs Arch. Pharmacol., 360, 262-269 (1999).

12) Komiya M, Takeuchi T, Harada E. Lemon oil vapor causes an antistress effect via modulating the 5-HT and DA activities in mice. Behav. Brain Res., 172, 240-249 (2006).

13) Elisabetsky E, Marschner J, Onofre Souza D. Effects of linalool on glutamatergic system in the rat cerebral cortex. Neurochem. Res., 20, 461-465 (1995).

14) Dayawansa S, Umeno K, Takakura H, Hori E, Tabuchi E, Nagashima Y, Oosu H, Yada Y, Suzuki T, Ono T, Nishijo H. Autonomic responses during inhalation of natural fragrance of "Cedrol" in humans. Auton. Neurosci., 108, 79-86 (2003).

15) Umeno K, Hori E, Tsubota M, Shojaku H, Miwa T, Nagashima Y, Yada Y, Suzuki T, Ono T, Nishijo H. Effects of direct cedrol inhalation into the lower airway on autonomic nervous activity in totally laryngectomized subjects. Br. J. Clin. Pharmacol., 65, 188-196 (2008).

16) Hori E, Shojaku H, Watanabe N, Kawasaki Y, Suzuki M, de Araujo MFP, Nagashima Y, Yada Y, Ono T, Nishijo H. Effects of direct cedrol inhalation into the lower airway on brain hemodynamics in totally laryngectomized subjects. Auton. Neurosci., 168, 88-92 (2012).

17) Kagawa D, Jokura H, Ochiai R, Tokimitsu I, Tsubone H. The sedative effects and mechanism of action of cedrol inhalation with behavioral pharmacological evaluation. Planta Med., 69, 637-641 (2003).

18) Yada Y, Sadachi H, Nagashima Y, Suzuki T. Overseas survey of the effect of cedrol on the autonomic nervous system in three countries. J. Physiol. Anthropol., 26, 349-354 (2007).

19) Zhang K, Yao L. The anxiolytic effect of Juniperus virginiana L. essential oil and determination of its active constituents. Physiol. Behav., 189, 50-58 (2018).

20) Donner NC, Lowry CA. Sex differences in anxiety and emotional behavior. Pflugers Arch., 465, 601-626 (2013).

21) Lynch WJ. Sex differences in vulnerability to drug self-administration. Exp. Clin. Psychopharmacol., 14, 34-41 (2006).

22) Simpson J, Ryan C, Curley A, Mulcaire J, Kelly JP. Sex differences in baseline and drug-induced behavioural responses in classical behavioural tests. Prog. Neuropsychopharmacol. Biol. Psychiatry, 37, 227-236 (2012)

23) Mestre ZL, Melhorn SJ, Askren MK, Tyagi V, Gatenby C, Young L, Mehta S, Webb MF, Grabowski TJ, Schur EA. Effects of anxiety on caloric intake and satiety-related brain activation in women and men. Psychosom. Med., 78, 454-464 (2016).

24) Carreira MB, Cossio R, Britton GB. Individual and sex differences in high and low responder phenotypes. Behav. Processes, 136, 20-27 (2017).

25) Umezu T, Sakata A, Ito H. Ambulation-promoting effect of peppermint oil and identification of its active constituents. Pharmacol. Biochem. Behav., 69, 383-390 (2001).

26) Umezu T, Nagano K, Ito H, Kosakai K, Sakaniwa M, Morita M. Anticonflict effects of lavender oil and identification of its active constituents. Pharmacol. Biochem. Behav., 85, 713-721 (2006).

27) Silenieks LB, Koch E, Higgins GA. Silexan, an essential oil from flowers of Lavandula angustifolia, is not recognized as benzodiazepine-like in rats trained to discriminate a diazepam cue. Phytomedicine, 20, 172-177 (2013).

28) Varty GB, Morgan CA, Cohen-Williams ME, Coffin VL, Carey GJ. The gerbil elevated plus-maze I: behavioral characterization and pharmacological validation. Neuropsychopharmacology, 27, 357-370 (2002).

29) Kalisch R, Schubert M, Jacob W, Kessler MS, Hemauer R, Wigger A, Landgraf R, Auer DP. Anxiety and hippocampus volume in the rat. Neuropsychopharmacology, 31, 925-932 (2006).

30) de Araújo Godinho MA, Meneghini L, Lucinda AM, Borges FRM, Sakae DY, Marino Neto J, Paschoalini MA, de Lima TCM, Faria MS. An approach to evaluate the ability of rats to discriminate different levels of illumination in the plus maze test: effects of scopolamine. Behav. Brain Res., 180, 86-94 (2007).

31) Biala G, Kruk M. Calcium channel antagonists suppress cross-tolerance to the anxiogenic effects of $d$-amphetamine and nicotine in the mouse elevated plus maze test. Prog. Neuropsychopharmacol. Biol. Psychiatry, 32, 54-61 (2008).

32) Bourin M, Hascoët M. The mouse light/dark box test. Eur. J. Pharmacol., 463, 55-65 (2003).

33) Nku C, Oghale G, Ajiwhen I. Locomotor behaviour and anxiety in the open field and light/dark box in CD1 mice treated with aspirin, cataflam and ethanolic extract of Cannabis sativa. British Journal of Medicine and Medical Research, 6, 563-572 (2015).

34) Costa CARA, Cury TC, Cassettari BO, Takahira RK, Flório JC, Costa M. Citrus aurantium L. essential oil exhibits anxiolytic-like activity mediated by $5-\mathrm{HT}_{1 \mathrm{~A}}$-receptors and reduces cholesterol after repeated oral treatment. BMC Complement. Altern. Med., 13, 42 (2013).

35) Zhang N, Zhang L, Feng LY, Yao L. The anxiolytic effect of essential oil of Cananga odorata exposure on mice and determination of its major active constituents. Phytomedicine, 23, 1727-1734 (2016).

36) He D, Wang X, Zhang P, Luo X, Li X, Wang L, Li S, Xu Y. Evaluation of the anxiolytic and antidepressant activities of the aqueous extract from Camellia euphlebia Merr. ex Sealy in mice. Evid. Based Complement. Alternat. Med., 2015, 618409 (2015).

37) Ramos A. Animal models of anxiety: do I need multiple tests? Trends Pharmacol. Sci., 29, 493-498 (2008).

38) Kulesskaya N, Voikar V. Assessment of mouse anxiety-like behavior in the light-dark box and open-field arena: Role of equipment and procedure. Physiol. Behav., 133, 30-38 (2014). 
39) Hoyer D, Hannon JP, Martin GR. Molecular, pharmacological and functional diversity of 5-HT receptors. Pharmacol. Biochem. Behav., 71, 533-554 (2002).

40) Paulus MP, Stein MB. An insular view of anxiety. Biol. Psychiatry, 60, 383-387 (2006).

41) Sasaki-Adams DM, Kelley AE. Serotonin-dopamine interactions in the control of conditioned reinforcement and motor behavior. $\mathrm{Neu}$ ropsychopharmacology, 25, 440-452 (2001).

42) Aoshima H, Hamamoto K. Potentiation of GABA $\mathrm{A}$ receptors expressed in Xenopus Oocytes by perfume and phytoncid. Biosci. Biotechnol. Biochem., 63, 743-748 (1999).

43) Ravenelle R, Neugebauer NM, Niedzielak T, Donaldson ST. Sex differences in diazepam effects and parvalbumin-positive GABA neurons in trait anxiety Long Evans rats. Behav. Brain Res., 270, 68-74 (2014)

44) Jin L, Wu F, Li X, Li H, Du C, Jiang Q, You J, Li S, Xu Y. Antidepressant effects of aqueous extract from Acanthopanax senticosus in mice. Phytother. Res., 27, 1829-1833 (2013).

45) Kostrzewa RM, Reader TA, Descarries L. Serotonin neural adaptations to ontogenetic loss of dopamine neurons in rat brain. J. Neurochem., 70, 889-898 (1998).

46) Palanza P. Animal models of anxiety and depression: how are females different? Neurosci. Biobehav. Rev., 25, 219-233 (2001).

47) Griebel G, Holmes A. 50 years of hurdles and hope in anxiolytic drug discovery. Nat. Rev. Drug Discov., 12, 667-687 (2013).

48) Wilson MA, Burghardt PR, Ford KA, Wilkinson MB, Primeaux SD. Anxiolytic effects of diazepam and ethanol in two behavioral models: comparison of males and females. Pharmacol. Biochem. Behav., 78, 445-458 (2004).

49) Díaz-Véliz G, Butrón S, Benavides MS, Dussaubat N, Mora S. Gender, estrous cycle, ovariectomy, and ovarian hormones influence the effects of diazepam on avoidance conditioning in rats. Pharmacol. Biochem. Behav., 66, 887-892 (2000).

50) Hodosy J, Zelmanová D, Majzúnová M, Filová B, Malinová M, Ostatníková D, Celec P. The anxiolytic effect of testosterone in the rat is mediated via the androgen receptor. Pharmacol. Biochem. Behav., 102, 191-195 (2012).
51) Hill MN, Karacabeyli ES, Gorzalka BB. Estrogen recruits the endocannabinoid system to modulate emotionality. Psychoneuroendocrinology, 32, 350-357 (2007).

52) Marcondes FK, Miguel KJ, Melo LL, Spadari-Bratfisch RC. Estrous cycle influences the response of female rats in the elevated plusmaze test. Physiol. Behav., 74, 435-440 (2001).

53) McCarthy MM, McDonald CH, Brooks PJ, Goldman D. An anxiolytic action of oxytocin is enhanced by estrogen in the mouse. Physiol. Behav., 60, 1209-1215 (1996)

54) Mora S, Dussaubat N, Díaz-Véliz G. Effects of the estrous cycle and ovarian hormones on behavioral indices of anxiety in female rats. Psychoneuroendocrinology, 21, 609-620 (1996).

55) Pfaff DW, Phillips MI, Rubin RT. Principles of honmone/behavior relations. Elsevier Academic Press, Burlington, MA, U.S.A. (2004).

56) Aoki M, Shimozuru M, Kikusui T, Takeuchi Y, Mori Y. Sex differences in behavioral and corticosterone responses to mild stressors in ICR mice are altered by ovariectomy in peripubertal period. Zoolog. Sci., 27, 783-789 (2010).

57) Xiao L, Becker JB. Quantitative microdialysis determination of extracellular striatal dopamine concentration in male and female rats: effects of estrous cycle and gonadectomy. Neurosci. Lett., 180, 155-158 (1994)

58) Simpson J, Kelly JP. An investigation of whether there are sex differences in certain behavioural and neurochemical parameters in the rat. Behav. Brain Res., 229, 289-300 (2012).

59) Becker JB, Hu M. Sex differences in drug abuse. Front. Neuroendocrinol., 29, 36-47 (2008).

60) Shams WM, Cossette M, Shizgal P, Brake WG. 17 $\beta$-Estradiol locally increases phasic dopamine release in the dorsal striatum. $\mathrm{Neu}$ rosci. Lett., 665, 29-32 (2018).

61) Becker JB. Direct effect of $17 \beta$-estradiol on striatum: sex differences in dopamine release. Synapse, 5, 157-164 (1990).

62) Estrada-Camarena E, Fernández-Guasti A, López-Rubalcava C. Participation of the $5-\mathrm{HT}_{1 \mathrm{~A}}$ receptor in the antidepressant-like effect of estrogens in the forced swimming test. Neuropsychopharmacology, 31, 247-255 (2006). 